\title{
Personality disorders and normal personality
}

\section{dimensions in obsessive-compulsive disorder}

\author{
JACK SAMUELS, GER ALD NESTADT, O. JOSEPH BIENVENU, \\ PAUL T. COSTA, Jr, MARK A. RIDDLE, KUNG-YEE LIANG, \\ RUDOLF HOEHN-SARIC, MARCO A. GRADOS \\ and BERNADETTE A. M. CULLEN
}

\begin{abstract}
Background Little is known about personality disorders and normal personality dimensions in relatives of patients with obsessive-compulsive disorder (OCD)
\end{abstract}

Aims To determine whether specific personality characteristics are part of a familial spectrum of OCD.

\section{Method Clinicians evaluated}

personality disorders in 72 OCD case and

72 control probands and 198 case and 207 control first-degree relatives. The selfcompleted Revised NEO Personality Inventory was used for assessment of normal personality dimensions. The prevalence of personality disorders and scores on normal personality dimensions were compared between case and control probands and between case and control relatives.

Results Case probands and case relatives had a high prevalence of obsessive-compulsive personality disorder (OCPD) and high neuroticism scores. Neuroticism was associated with OCPD in case but not control relatives.

Conclusions Neuroticism and OCPD may share a common familial aetiology with OCD.

Declaration of interest Supported by National Institutes of Health grants ROI MH502/4 and NIH/NCRR/OPDGCRC RR00052.
Over the past 60 years, psychiatrists have reported that specific abnormal personality traits frequently occur in patients with obsessive-compulsive disorder (OCD; Lewis, 1936). Early studies emphasised that obsessional or 'anankastic' features were frequent in patients with obsessional neurosis, as well as in their first-degree relatives (Kringlen, 1965). However, there have been marked differences between subsequent studies in the reported prevalence of obsessive-compulsive and other personality disorders in patients with OCD (Nestadt et al, 1991; Black \& Noyes, 1997). Furthermore, there have been few studies of normal personality features in individuals with OCD (Pfohl et al, 1990; Bejerot et al, 1998). In addition, little is known about the personality characteristics of relatives of patients with OCD. In the current study, we evaluated personality disorders and normal personality dimensions in OCD cases and controls and their first-degree relatives. The aim was to determine whether specific personality characteristics are part of a familial spectrum of OCD.

\section{METHOD}

\section{Sample}

The study was undertaken as part of the Johns Hopkins OCD Family Study (Nestadt et al, 2000). Adult OCD probands were randomly selected from five speciality treatment sites in the Baltimore, Maryland and Washington, DC areas. All adult patients with a diagnosis of OCD who were first evaluated in these centres in the 3 years prior to the initiation of the study were listed, and a sample from each site was randomly selected to participate in the study, whether currently ill or not. Interviews were completed for 80 case probands and 343 of their first-degree relatives. Control probands were identified in the community by a random-digit dialling procedure that individually matched control to case probands on gender, race, age (within 10 years), telephone exchange and whether medical care had been received in the preceding year. Interviews were completed for 73 control probands and 300 of their first-degree relatives. Case probands were included if they met DSM-IV (American Psychiatric Association, 1994) criteria for OCD as diagnosed by the consensus procedure and if they scored higher than 15 on the YaleBrown Obsessive Compulsive Scale (YBOCS; Goodman et al, 1989) during the worst episode. Case probands were excluded if they were diagnosed with schizophrenia, mental retardation, dementia or Tourette's disorder, or if OCD occurred exclusively during a major depressive episode. Control probands were excluded if any of these disorders, or OCD, was present but otherwise were representative of persons residing in the communities in which the cases lived. There were no diagnostic exclusions for case or control relatives; as reported previously (Nestadt et al, 2000), 38 of the case relatives and 8 of the control relatives were diagnosed with OCD.

\section{Diagnostic procedures}

After obtaining informed written consent, clinicians (psychiatrists or PhD-level clinical psychologists) examined subjects using the fourth revision of the Schedule for Affective Disorders and Schizophrenia Lifetime Anxiety (Mannuzza et al, 1986), which was adapted to include sections on tic disorders and impulse control disorders; the OCD section was also elaborated to include the Y-BOCS (Goodman et al, 1989) and additional material on course of symptoms. In addition to conducting direct interviews, the clinicians contacted a knowledgeable informant for each subject to obtain collateral information for diagnostic evaluation. The interviewers were blinded as to whether the subjects were probands or relatives or were from case or control families. All probands were interviewed in person. Approximately $30 \%$ of the relatives were not available for direct interview because they were deceased, refused to participate or the proband refused contact; these relatives were older than direct participants (mean age $=53.3$ $v$. 43.5 years, $t(641$ d.f. $)=6.20, P<0.001)$ and a greater proportion were males $\left(60 \% \quad v . \quad 44 \%, \quad \chi^{2} \quad(1 \quad\right.$ d.f. $)=14.5$, 
$P<0.001$ ). For these subjects, informant interviews were conducted with two individuals who were familiar with the subject, using an adapted version of the Family Informant Schedule and Criteria (Mannuzza et al, 1985). For every subject, a DSM-IV Diagnostic Assignment Form was completed; this form was designed to record the presence of all necessary diagnostic criteria and guide the assignment of diagnoses according to DSM-IV criteria.

All available diagnostic materials (evaluation by the clinical examiner, informant interview, clinical case summary, medical records and audiotapes) were reviewed independently by two expert psychiatrists. The diagnosticians were blinded as to whether the subject was a proband or relative or from a case or control family. All psychiatric diagnoses were made according to strict DSM-IV criteria.

The Revised Structured Instrument for the Diagnosis of Personality Disorders (SIDP-R; Pfohl et al, 1989) was used for the assessment of all DSM-IV personality disorders in all subjects over the age of 15 years who were examined directly; this instrument was also used to collect collateral information about directly examined subjects from informants. Subjects for whom only informant interviews were obtained were assessed using only the obsessive-compulsive personality disorder (OCPD) items from this instrument, and this information was used in the relevant analyses.

The Revised NEO Personality Inventory (NEO PI-R; Costa \& McCrae, 1992), paper-and-pencil form, was selfcompleted by subjects who were interviewed directly and this was used for the assessment of the five domains of normal personality as construed by the Five-Factor Model: neuroticism, extraversion, openness, agreeableness and conscientiousness. Each domain is represented by six specific scales that measure facets of the domain. Neuroticism facets are anxiety, angry hostility, depression, self-consciousness, impulsiveness and vulnerability. Extraversion facets are warmth, gregariousness, assertiveness, activity, excitement-seeking and positive emotions. Openness facets are fantasy, aesthetics, feelings, actions, ideas and values. Agreeableness facets are trust, straightforwardness, altruism, compliance, modesty and tender-mindedness. Conscientiousness facets are competence, order, dutifulness, achievement-striving, self-discipline and deliberation. The $t$-scores
Table I Prevalence of DSM-IV personality disorders in obsessive-compulsive disorder case and control probands

\begin{tabular}{|c|c|c|c|}
\hline & $\begin{array}{l}\text { Case probands } \\
\qquad(n=72) \\
\text { Number }(\%)\end{array}$ & $\begin{array}{l}\text { Control probands } \\
\qquad \begin{array}{c}(n=72) \\
\text { Number }(\%)\end{array}\end{array}$ & $P^{\prime}$ \\
\hline Schizotypal & $0(0)$ & I (I.4) & 0.99 \\
\hline Schizoid & $0(0)$ & $0(0)$ & -2 \\
\hline Paranoid & $3(4.3)$ & $2(2.8)$ & 0.68 \\
\hline Any 'cluster A' disorder & $3(4.4)$ & $2(2.8)$ & 0.67 \\
\hline Antisocial & $0(0)$ & $0(0)$ & -2 \\
\hline Borderline & $5 \quad(5.7)$ & $2(2.8)$ & 0.27 \\
\hline Histrionic & $3(4.2)$ & $0(0)$ & 0.25 \\
\hline Narcissistic & $5(6.9)$ & $0(0)$ & 0.06 \\
\hline Any 'cluster B' disorder & $9(12.9)$ & $2(2.8)$ & 0.06 \\
\hline Avoidant & II (I5.3) & I (I.4) & 0.004 \\
\hline Dependent & $3(4.2)$ & $0(0)$ & 0.25 \\
\hline Obsessive-compulsive & $23(32.4)$ & $4(5.6)$ & $<0.001$ \\
\hline Any 'cluster C' disorder & $26(36.6)$ & $5(6.9)$ & $<0.001$ \\
\hline Any personality disorder & 31 (44.3) & $7(10.0)$ & $<0.001$ \\
\hline
\end{tabular}

I. Fisher's exact test.

2. Indeterminate.

for the five domains and 30 facets were calculated according to the method of Costa \& McCrae (1992), which uses different reference means and standard deviations for men and women. These distributions have a mean of 50 and a standard deviation of 10 . The $t$-scores are considered 'average' in the range 45-55. Scores less than 45 are considered 'low', those in the range 56-65 are considered 'high' and those greater than 65 are considered 'very high'.

\section{Statistical analysis}

The prevalence of personality disorders was compared in case and control probands and case and control relatives using Fisher's exact test. The domain and facet scores were compared in case and control probands and case and control relatives using Student's $t$-test. To evaluate the relationship between neuroticism and OCPD in relatives, the prevalence of OCPD across neuroticism score categories was compared using the $\chi^{2}$ test for trend. In addition, the association between neuroticism (as a continuous dimension) and OCPD was evaluated using logistic regression. Given the exploratory nature of this study, each test was two-sided with $\alpha=0.05$.

\section{RESULTS}

\section{Probands}

The assessment of personality disorders using the SIDP-R examination was completed for 72 case probands and 72 control probands. The two groups of probands were similar with respect to gender distribution: $51 \%$ of the case probands, compared to $61 \%$ of the control probands, were female. The mean age at interview in case probands was similar to that in control probands: 36.3 and 38.4 years, respectively.

As shown in Table 1 , nearly $45 \%$ of case probands had a personality disorder, which is over four times greater than the $10 \%$ prevalence in controls (Fisher's exact test, $\quad P<0.001)$. Avoidant personality disorder was more prevalent in case than in control probands (15.3 v. 1.4\%, $P=0.004)$, as was OCPD (32.4 v. 5.6\%, $P<0.001)$. Case probands also had a higher prevalence of narcissistic personality disorder, but the difference was not statistically significant. 
Table 2 The NEO personality domain t-scores in obsessive-compulsive disorder case and control probands

\begin{tabular}{lcccc}
\hline & $\begin{array}{c}\text { Case probands } \\
(n=65) \\
\text { Mean (s.d.) }\end{array}$ & $\begin{array}{c}\text { Control probands } \\
(n=72) \\
\text { Mean (s.d.) }\end{array}$ & $\begin{array}{c}\text { Test statistic } \\
(\text { d.f. })\end{array}$ & $P$ \\
\hline Neuroticism & $64.0(12.5)$ & $49.8(11.0)$ & $t(135)=7.08$ & $<0.001$ \\
Extraversion & $47.4(12.6)$ & $52.0(10.0)$ & $t(135)=2.39$ & 0.02 \\
Openness & $53.5(11.4)$ & $52.3(10.9)$ & $t(135)=0.62$ & 0.54 \\
Agreeableness & $48.9(11.3)$ & $43.8(12.5)$ & $t(135)=2.50$ & 0.01 \\
Conscientiousness & $43.3(10.5)$ & $46.2(13.3)$ & $t(135)=1.43$ & 0.16 \\
\hline
\end{tabular}

As shown in Table 2, case probands scored much higher on neuroticism than did control probands $(64.0 v .49 .8 ; t(135$ d.f. $)=7.1, \quad P<0.001)$. In addition, case probands scored significantly lower on extraversion $\quad(47.4 \quad v . \quad 52.0 ; \quad t(135$ d.f. $)=2.4, P=0.02$ ) and significantly higher on agreeableness domains (48.9 v. 43.8; $t(135$ d.f. $)=2.5, P=0.01)$, although their mean scores were close to the population means for these scales. Mean openness and conscientiousness scores were not significantly different between the two groups.

All facets of neuroticism (anxiety, angry hostility, depression, self-consciousness, impulsiveness, and vulnerability) were significantly higher in case probands and above the 'average' range, especially the anxiety facet, with mean scores of 65.5 and 48.7 in the case and control probands, respectively $(t(135$ d.f. $)=9.68$, $P<0.001)$. Case probands were also high on two openness facets: they were more open to fantasy (mean score of 56.1 and 52.6 in case and control probands, respectively; $t(135$ d.f. $)=2.14, \quad P=0.035)$ and more open to feelings (mean scores of 55.5 and 51.2 in case and control probands, respectively; $t(135$ d.f. $)=2.53$, $P=0.01)$. In addition, case probands scored below the average range on two conscientiousness facets: they scored lower on competence (43.5 v. 51.0; $t(135$ d.f. $)=3.43, \quad P=0.001)$ and selfdiscipline $(36.9$ v. $46.8 ; t(135$ d.f. $)=4.16$, $P<0.001)$ than control probands. Case probands also scored significantly lower on assertiveness and openness to actions and significantly higher on straightforwardness, modesty and tender-mindedness than did control probands; however, scores for these facets were within the 'normal' range.

\section{Relatives} tives of case probands and 207 relatives of control probands were evaluated directly using the SIDP-R. The OCPD assessments (from direct interviews or informant-only interviews) were available for 296 case relatives and 242 control relatives. The relatives differed somewhat with respect to gender and age distributions: $51.4 \%$ of the case relatives, compared to $42.6 \%$ of the control relatives, were female $\left(\chi^{2}\right)(1$
To assess personality disorders, 198 reladisorder case and control probands

I. Fisher's exact test.

2. Indeterminate.

3. Evaluated for 296 case relatives and 242 control relatives. d.f. $=4.1, P=0.04)$ and the mean ages at interview were 48.9 and 45.6 years in case and control relatives, respectively $(t(536$ d.f. $=2.26, P=0.02$ ). However, controlling for gender and age in subsequent analyses did not substantially affect the results (data not shown).

As shown in Table 3, 21\% of case relatives had a personality disorder, which is nearly twice the prevalence of $10.7 \%$ in the control relatives (Fisher's exact test, $P=0.005)$. Obsessive-compulsive personality disorder was twice as prevalent in case compared to control relatives $(11.5 \%$ v. $5.8 \%, P=0.02$ ).

As shown in Table 4, case relatives scored significantly higher than control relatives on neuroticism. At the neuroticism facet level, case relatives scored significantly higher on anxiety (mean scores of 53.6 and 49.1 in case and control relatives, respectively; $t(350$ d.f. $)=3.80, P<0.001)$, significantly higher on self-consciousness $(51.5$ $v .48 .5 ; t(350$ d.f. $)=2.65, P=0.01)$ and significantly higher on vulnerability to stress (51.2 v. 48.6; $t$ (350 d.f.) $=2.23, P=0.03$ ).

Scores on other personality domains were not different between the two groups. At the facet level, case relatives scored

Table 3 Prevalence of DSM-IV personality disorders in first-degree relatives of obsessive-compulsive

\begin{tabular}{|c|c|c|c|}
\hline & $\begin{array}{l}\text { Case relatives } \\
\qquad(n=198) \\
\text { Number }(\%)\end{array}$ & $\begin{array}{l}\text { Control relatives } \\
\qquad(n=207) \\
\text { Number (\%) }\end{array}$ & $P^{\prime}$ \\
\hline Schizotypal & I (I.5) & $0(0)$ & 0.50 \\
\hline Schizoid & $2(1.0)$ & $2(1.0)$ & 0.99 \\
\hline Paranoid & $3(1.5)$ & $0(0)$ & 0.12 \\
\hline Any 'cluster A' disorder & $4(2.0)$ & $2(1.0)$ & 0.44 \\
\hline Antisocial & $0(0)$ & $2(1.0)$ & 0.50 \\
\hline Borderline & $2(1.0)$ & I (0.5) & 0.62 \\
\hline Histrionic & $0(0)$ & $0(0)$ & -2 \\
\hline Narcissistic & $6(3.0)$ & I (0.5) & 0.06 \\
\hline Any 'cluster B' disorder & $6(3.1)$ & $4(2.0)$ & 0.54 \\
\hline Avoidant & $5(2.5)$ & $3(1.4)$ & 0.49 \\
\hline Dependent & $3(1.5)$ & $0(0)$ & 0.12 \\
\hline Obsessive-compulsive $^{3}$ & $34(11.5)$ & $14(5.8)$ & 0.02 \\
\hline Any 'cluster C' disorder & $38(18.3)$ & $17(8.2)$ & 0.003 \\
\hline Any personality disorder & $44(21.3)$ & $22(10.7)$ & 0.005 \\
\hline
\end{tabular}


Table 4 NEO personality domain $t$-scores in first-degree relatives of obsessive-compulsive disorder case and control probands

\begin{tabular}{lcccc}
\hline & $\begin{array}{c}\text { Case relatives } \\
(n=168) \\
\text { Mean (s.d.) }\end{array}$ & $\begin{array}{c}\text { Control relatives } \\
(n=184) \\
\text { Mean (s.d.) }\end{array}$ & $\begin{array}{c}\text { Test statistic } \\
\text { (d.f.) }\end{array}$ & $P$ \\
\hline Neuroticism & $52.1(11.8)$ & $49.0(10.7)$ & $t(350)=2.60$ & 0.01 \\
Extraversion & $48.7(10.3)$ & $49.7(10.3)$ & $t(350)=0.91$ & 0.36 \\
Openness & $49.4(11.6)$ & $49.9(9.9)$ & $t(350)=0.44$ & 0.66 \\
Agreeableness & $50.7(9.9)$ & $49.6(I 1.4)$ & $t(350)=1.00$ & 0.32 \\
Conscientiousness & $49.2(12.1)$ & $47.3(10.5)$ & $t(350)=1.57$ & 0.12 \\
\hline
\end{tabular}

significantly lower on excitement-seeking (46.6 v. 50.3 in case and control relatives, respectively; $t(350$ d.f. $)=3.33, P=0.001)$, significantly lower on openness to actions (47.8 v. $51.2 ; t(350$ d.f. $)=2.78, P=0.006)$ and significantly higher on order (48.2 $v$. $45.4 ; t(350$ d.f. $)=2.36, P=0.02$ ).

As shown in Table 5 , in control relatives the prevalence of OCPD was similar across neuroticism categories. In contrast, in case relatives, the prevalence of OCPD increased from lowest to successively higher categories of neuroticism $\left(\chi^{2}\right.$ trend $(1$ d.f. $)=6.40, P=0.01)$. Similarly, when evaluated as a continuous dimension, neuroticism was associated with OCPD in case relatives (odds ratio per unit increase in neuroticism $=1.06,95 \% \mathrm{CI}$ 1.02-1.10, $P=0.004$ ) but not in control relatives; however, the interaction term (neuroticism $\times$ relative group) was not statistically significant $(P=0.30)$. In case relatives, the relationship between neuroticism and OCPD did not change appreciably after controlling in the logistic

model for the presence of OCD or when the analysis was restricted to relatives without OCD.

\section{DISCUSSION}

\section{Probands}

Results from this study indicate that OCD probands and controls differ with respect to specific features of disordered and normal personality. Compared to controls, OCD probands have a significantly greater prevalence of DSM-IV 'anxious' (cluster C) personality disorders in general and avoidant and obsessive-compulsive personality disorders in particular. Our findings that $32 \%$ of OCD probands have OCPD and about $15 \%$ have avoidant personality are in accord with several recent studies (Stanley et al, 1990; Black et al, 1993; Ravizza et al, 1995; Skodol et al, 1995). In contrast, we found that other personality disorders were not significantly more
Table 5 Prevalence of DSM-IV obsessive-compulsive personality disorder (OCPD) in first-degree case and control relatives by neuroticism $t$-scores

\begin{tabular}{|c|c|c|c|c|}
\hline \multirow{2}{*}{$\begin{array}{l}\text { Neuroticism } \\
\text { score }\end{array}$} & \multicolumn{2}{|c|}{ Case relatives $(n=165)$} & \multicolumn{2}{|c|}{ Control relatives $(n=176)$} \\
\hline & Number & Number (\%) with OCPD & Number & Number (\%) with OCPD \\
\hline$<45$ & 48 & $3(6.3)$ & 73 & $3(4.1)$ \\
\hline $45-55$ & 55 & $5(9.1)$ & 52 & $2(3.8)$ \\
\hline $56-65$ & 37 & $5(13.5)$ & 40 & $4(10.0)$ \\
\hline$>65$ & 25 & $8(32.0)$ & II & I (9.1) \\
\hline $\begin{array}{l}\text { Significance } \\
\left(\chi^{2} \text { test for trend) }\right.\end{array}$ & \multicolumn{2}{|c|}{$\chi^{2}(\mathrm{I}$ d.f. $)=6.40, P=0.0 \mathrm{I}$} & \multicolumn{2}{|c|}{$\chi^{2}(\mathrm{I}$ d.f. $)=I .37, P=0.24$} \\
\hline
\end{tabular}

prevalent in the case than in control probands.

Case probands scored substantially higher on the neuroticism domain and all its facets. In addition, two openness facets were markedly higher in case probands (openness to fantasy and openness to feelings), whereas two conscientiousness facets were markedly lower in case probands (competence and self-discipline). The mean scores in case probands were very different from both control and the population means. This profile presents a coherent description of some individuals with OCD as highly neurotic, tenderminded people who lack the ability to carry tasks to completion.

Given the long-standing clinical impression that conscientiousness is characteristic of individuals with OCPD (Janet, 1903; Freud, 1953; Pitman, 1987), it may seem surprising that OCD case probands did not score higher than controls on the conscientiousness domain and, in fact, scored significantly lower on competence and self-discipline facets. Perhaps individuals with OCD judge that they are not performing at the level required by their own high standards; alternatively, worry and doubt may interfere with their productivity. It also is interesting that case probands score higher on impulsiveness (a facet of neuroticism) and openness to fantasy, which may reflect their difficulty in resisting intrusive thoughts. It should be noted that the majority of OCD case probands did not have OCPD and may differ on normal personality dimensions from probands with OCPD.

There have been few previous studies of normal personality features in individuals with OCD. Pfohl et al (1990) found that, compared with non-ill controls, patients with OCD scored very high on 'harm avoidance', high on 'reward dependence' and low on 'novelty-seeking' dimensions of the Tridimensional Personality Questionnaire (Cloninger, 1986). Bejerot et al (1998) found that, compared with healthy controls, patients with OCD scored significantly higher on 'harm avoidance' and significantly lower on 'self-directedness' and 'cooperativeness' dimensions of the Temperament and Character Inventory (Cloninger et al, 1993). Further research on the comparability of different personality instruments is needed before we can evaluate the consistency between these findings and the results of the current study. 


\section{Relatives}

The first-degree relatives of OCD probands and controls differed with respect to specific aspects of disordered and normal personality. Obsessive-compulsive personality disorder was twice as common in the case relatives; in contrast, occurrence of other personality disorders was not significantly different between the two groups of relatives. Case relatives also scored significantly higher on neuroticism, but not other domains. Case relatives scored significantly lower on excitement-seeking and openness to actions and significantly higher on order, a constellation of traits consistent with obsessionality (Kringlen, 1965).

To our knowledge, this is the first family study to demonstrate that high neuroticism and OCPD are more common in relatives of OCD cases compared with relatives of controls. These personality characteristics may share a common familial aetiology with OCD. Neuroticism, OCPD and OCD may be alternative expressions of the same underlying vulnerability. Each of these phenotypes may represent a different level of severity along a continuum, or additional factors may be necessary for differentiation into the specific clinical phenomena. Alternatively, these three phenotypes may be distinct entities, one a direct expression of the vulnerability and the other(s) emerging secondarily. This is supported by the finding of a relationship between neuroticism and OCPD only in the relatives of OCD cases; however, the interaction term was not statistically significant and this relationship needs to be explored in larger samples. It may be that neuroticism is transmitted in these families, as has been proposed by others (Andrews et al, 1990), but that in order for OCPD to emerge, additional genetic or environmental factors are required. It should be noted that OCD may be aetiologically heterogeneous and that the relationship to neuroticism and OCPD is important only in a subgroup of individuals. Of course, although the current study focused on OCD, high neuroticism may predispose to a variety of other anxiety disorders as well (Trull \& Sher, 1994).

\section{Limitations}

The major limitation of the current study is that information on normal personality and personality disorders other than OCPD was unavailable for the $36 \%$ of case relatives and $23 \%$ of control relatives who were not interviewed directly. Most of these subjects were deceased; on average, they were older and a greater proportion were men. The estimated odds of OCPD in case versus control relatives did not change appreciably after controlling for type of interview (direct or informant only) in a logistic model, and the relationship between relative group and neuroticism did not change after controlling for age and gender of the relative in a linear model (data not shown). Nevertheless, we do not know if the personality features of relatives who were not interviewed directly differ from those of participants, or if the different proportion of non-participation in case and control relatives introduced a bias in estimation of the prevalence of personality disorders and distribution of normal personality dimensions. In future family studies, it would be useful to collect informant information about all personality disorders; an observer-report version of the NEO (NEO $\mathrm{PI}-\mathrm{R}$ ) is available for the assessment of normal personality features (Costa \& McCrae, 1992).

Another potential limitation of the study is the problem of state-trait confounding: that is, the assessment of personality features by subjects and their informants might be influenced by current symptoms (Reich et al, 1986). It should be noted that probands were not selected, or scheduled for interview, on the basis of being in active treatment or currently ill. Furthermore, the examining clinician attempted to elicit enduring personality features over the subject's entire life span.

Others have proposed that obsessional personality features precede the development of obsessive-compulsive symptoms (Sandler \& Hazari, 1960) and that neuroticism increases the vulnerability to development of several psychiatric disorders (McHugh \& Slavney, 1986). In this retrospective study, we evaluated the reported age at onset of obsessive-compulsive symptoms but not obsessive-compulsive personality features. Therefore, the results cannot inform as to whether the development of OCPD precedes or follows the development of OCD. Longitudinal studies are required to elucidate the temporal relationship between neuroticism, OCPD, OCD and other anxiety disorders.

\section{Clinical implications}

Despite these limitations, the results emphasise the clinical importance of tem- peramental features in individuals with OCD. Patients with OCD who have personality disorders may have poorer response to treatment (Baer et al, 1992), and symptom reduction may not resolve all the difficulties that these patients experience. Moreover, it is important for clinicians to recognise that temperamental difficulties are common in the relatives of these patients and may influence the course of treatment. Finally, the findings suggest that personality characteristics are important in understanding OCD, and further investigation of neuroticism and obsessive-compulsive personality traits in families may help to elucidate the pathogenesis of the disorder (Lyons et al, 1997).

\section{ACKNOWLEDGEMENTS}

The authors thank: Dr David Pauls, Dr Kathleen Merikangas, Dr Abby Fyer and Dr Salvatore Mannuzza for consultation in this study; Dr Dennis Murphy, Dr Ben Greenberg, Dr Sally Winston, Ms Donna Burns and Ms Dorinda Schultz for access to their clinic patients; and Dr Jennifer Hahn, Dr David Wellen, Dr Ruth Zitner, Dr Dan McCleod, Dr Malgorzata Lamacz, Ms Dorothy Carpenter, Ms Krista Vermillion and Ms Margaret Dees for their efforts in conducting the study.

\section{REFERENCES}

American Psychiatric Association (1994) Diagnostic and Statistical Manual of Mental Disorders (4th edn) (DSM-IV). Washington, DC: APA.

Andrews, G., Stewart, G., Allen, R., et al (1990) The genetics of six neurotic disorders: a twin study. Journal of Affective Disorders, 19, 23-29.

Baer, L., Jenike, M. A., Black, D. W., et al (1992) Effect of axis II diagnoses on treatment outcome with clomipramine in 55 patients with obsessive-compulsive disorder. Archives of General Psychiatry, 49, 862-866.

Bejerot, S., Schlette, P., Ekselius, L., et al (1998) Personality disorders and relationship to personality dimensions measured by the Temperament and Character Inventory in patients with obsessivecompulsive disorder. Acta Psychiatrica Scandinavica, 98 243-249.

Black, D. W., Noyes, R., Pfohl, B., et al (1993) Personality disorder in obsessive-compulsive volunteers, well comparison subjects, and their first-degree relatives. American Journal of Psychiatry, $\mathbf{I 5 0}$ 1226-1232.

_ \& Noyes, R., Jr (1997) Obsessive-compulsive disorder and axis II. International Review of Psychiatry, $\mathbf{9}$ $|I|-\mid 18$

Cloninger, C. R. (1986) A unified biosocial theory of personality and its role in the development of anxiety states. Psychiatric Developments, 3, 167-226.

—, Svrakic, D. M. \& Przybeck, T. R. (1993) A

psychobiological model of temperament and character. Archives of General Psychiatry, 50, 975-990. 
Costa, P. T., Jr \& McCrae, R. R. (1992) Revised NEO Personality Inventory (NEO PI-R) Professional Manual. Odessa, FL: Psychological Assessment Resources.

Freud, S. (1953) Character and anal eroticism. In Collected Papers (ed. J. Strachey), vol. 2, pp. 168-175. London: Hogarth.

Goodman, W. K., Price, L. H., Rasmussen, S. A., et (1989) The Yale-Brown Obsessive Compulsive Scale: I. Development, use and reliability. Archives of General Psychiatry, 46, 1006-1011.

Janet, P. (1903) Les Obsessions et al Psychasthénie. Paris Alcan.

Kringlen, E. (1965) Obsessional neurotics: a long-term follow-up. British Journal of Psychiatry, III, 709-722.

Lewis, A. (1936) Problems of obsessional illness. Proceedings of the Royal Society of Medicine, $\mathbf{3 6}$ 325-336.

Lyons, M. J., Tyrer, P., Gunderson, J., et al (1997) Heuristic models of comorbidity of axis I and axis II disorders. Journal of Personality Disorders, II 260-269.

\section{Mannuzza, S., Fyer, A. J., Endicott, J., et al (1985)} Family Informant Schedule and Criteria. New York, NY: Anxiety Family Study Unit, New York State Psychiatric Institute.

_, _ Klein, D. F., et al (1986) Schedule for Affective Disorders and Schizophrenia - Lifetime Version Modified for the Study of Anxiety Disorders (SADS$L A)$ : rationale and conceptual development. Journal of Psychiatric Research, 20, 317-325.

McHugh, P. R. \& Slavney, P. R. (1986) The Perspectives of Psychiatry. Baltimore: Johns Hopkins University Press.

Nestadt, G., Romanoski, A. J., Brown, C. H., et a (199I) DSM-IV compulsive personality disorder: an epidemiological survey. Psychological Medicine, 2I, $461-47 \mid$

_, Samuels, J., Bienvenu, O. J., et al (2000) A family study of obsessive compulsive disorder. Archives of General Psychiatry, 57, 358-363.

Pfohl, B., Blum, N., Zimmerman, M., et al (1989) Structured Interview for DSM-IIIR Personality SIDP-R. lowa City, IA: University of lowa College of Medicine.

_, Black, D. W., Noyes, R., et al (1990) A test of the tridimensional personality theory: association with diagnosis and platelet imipramine binding in obsessional-compulsive disorder. Biological Psychiatry 28, $4 \mid-46$.

Pitman, R. K. (1987) Pierre Janet on obsessivecompulsive disorder. Archives of General Psychiatry, 44 226-232.

Ravizza, L., Barzega, G., Bellino, S., et al (1995) Predictors of drug treatment response in obsessive-

\section{CLINICAL IMPLICATIONS}

Personality features may complicate the treatment of patients with obsessivecompulsive disorder (OCD).

Reduction of symptoms may not resolve all the difficulties that patients with OCD experience.

High neuroticism and obsessive-compulsive personality disorder (OCPD) are common in relatives of individuals with $O C D$.

\section{LIMITATIONS}

Approximately $30 \%$ of relatives were not interviewed directly.

- Informants were questioned about OCPD characteristics of subjects but not about other personality disorders or normal personality features.

- Assessment of personality features by subjects and their informants might be influenced by current symptoms.

JACK SAMUELS, PhD, GERALD NESTADT, MB, O. JOSEPH BIENVENU, MD, Department of Psychiatry and Behavioral Sciences, The Johns Hopkins University School of Medicine, Baltimore, MD; PAUL T. COSTA, Jr, PhD, Gerontology Research Center, National Institute on Aging, Baltimore, MD; MARK A. RIDDLE, MD, Department of Psychiatry and Behavioral Sciences and Department of Pediatrics, The Johns Hopkins University School of Medicine, Baltimore, MD; KUNG-YEE LIANG, PhD, Department of Biostatistics, The Johns Hopkins School of Public Health, Baltimore, MD; RUDOLF HOEHN-SARIC, MD, MARCO A. GRADOS, MD, BERNADETTE A. M. CULLEN, BCh, Department of Psychiatry and Behavioral Sciences, The Johns Hopkins University School of Medicine, Baltimore, MD, USA

Correspondence: Dr Jack Samuels, Department of Psychiatry and Behavioral Sciences, The Johns Hopkins Hospital, Meyer 4-18I, 600 N.Wolfe Street, Baltimore, MD 21287, USA

(First received 17 January 2000, final revision 9 June 2000, accepted 9 June 2000)

compulsive disorder. Journal of Clinical Psychiatry, $\mathbf{5 6}$ 368-373.

Reich, J., Noyes, R., Jr., Coryell, W., et al (1986) The effect of state anxiety on personality measurement. American Journal of Psychiatry, 143, 760-763.

Sandler, J. \& Hazari, A. (1960) The obsessional: on the psychological classification of obsessional character traits and symptoms. British Journal of Medical Psychology, 33, 113-122.
Skodol, A. E., Oldham, J. M., Hyler, S. E., et al (1995) Patterns of anxiety and personality disorder comorbidity. Journal of Psychiatric Research, 29, $361-374$.

Stanley, M. A., Turner, S. M. \& Borden, J. W. (1990) Schizotypal features in obsessive-compulsive disorder Comprehensive Psychiatry, 3I, 5II-518.

Trull, T. J. \& Sher, K. J. (1994) Relationship between the five-factor model of personality and axis I disorders in a non-clinical sample. Journal of Abnormal Psychology, 103. 350-360. 